\title{
Compañías de teatro y trabajo infantil en Medellín. El caso de Merceditas Escobar en Frutos de la Montaña (1939-1946)*
}

\section{Resumen:}

Este artículo es una contribución a la historia social de la infancia y del teatro en Colombia. Estudia la conformación y las giras de la Compañía Juvenil de Zarzuelas Frutos de la Montaña, de la cual hizo parte Merceditas Escobar, una de las niñas actrices más importante en Medellín, en la primera mitad del siglo XX. Los itinerarios de la compañía y de su principal actriz, permiten reflexionar sobre las representaciones sociales de la niñez y de género, las cuales dieron forma a un tratamiento particular de la problemática del trabajo infantil.

Palabras clave: Merceditas Escobar, teatro, zarzuela, trabajo infantil, representaciones sociales.

Referencia para citar este artículo: CORREA SERNA, Nancy Yohana (2017). "Compañías de teatro y trabajo infantil en Medellín. El caso de Merceditas Escobar en Frutos de la Montaña (1939-1946)". En Anuario de Historia Regional y de las Fronteras. 22 (1). pp. 89-112.

Nancy Yohana Correa Serna: Becaria de Colciencias. Integrante del grupo de investigación Prácticas, saberes y representaciones en Iberoamérica. Candidata a Doctora en Historia de la Universidad Nacional de Colombia, Sede Medellín. Historiadora de la Universidad de Antioquia. Magíster en Historia. Correo electrónico: nycorreas@unal.edu.co.

\footnotetext{
${ }^{*}$ El artículo es producto de la tesis de Maestría en Historia titulada Mujeres en escena. De Susana Tirado a Marina Ughetti y fue presentado en el VII Coloquio en Estudios Históricos Regionales de la Universidad Industrial de Santander.
} 


\title{
Theater and Child Labor Companies in Medellín. The Merceditas Escobar Case in Frutos de la Montaña (1939-1946)
}

\begin{abstract}
Summary:
This article is a contribution to the social history of childhood and theater in Colombia. It studies the formation and tours of the Youth Company from Zarzuelas-Fruits of the Mountain, which Merceditas Escobar was part of, one of the most important actresses in Medellin in the first half of the twentieth century. The itineraries of the company and its lead actress, allows the reflection on the social representations of childhood and gender, which gave way to a particular treatment of the child labor problem.
\end{abstract}

Keywords: Merceditas Escobar, Theatre, Zarzuela, Child Labor, Social Representations.

\section{Companhias de teatro e trabalho infantil em Medellin. $O$ caso de Merceditas Escobar em Frutos da Montanha (1939-1946)}

\section{Resumo:}

Este artigo é uma contribuição a historia social da infância e do teatro na Colômbia. Estuda a conformação e as excursões da Companhia Juvenil de Zarzuelas Frutos da Montanha, da qual fez parte Merceditas Escobar, uma das atrizes mirins más importantes de Medellin, na primeira metade do século XX. Os itinerários da companhia e de sua atriz principal permitem refletir sobre as representações sociais da infância e do gênero, as quais deram forma a um tratamento particular da problemática do trabalho infantil.

Palavra-chave: Merceditas Escobar, teatro, zarzuela, trabalho infantil, representações sociais. 


\section{Introducción}

Con la masificación de las radiodifusoras a finales de los años treinta y a principios de los cuarenta, y con su interés de ofrecer una programación variada para toda la familia, se popularizaron algunos programas infantiles o que contaban con la participación de niños y niñas. Dichos programas se fundamentaron en el gusto que el público local tenía por ver y por escuchar a los infantes en escena, en este caso, a través de la radio, gusto que había sido demostrado desde finales del siglo XIX, cuando en la ciudad se constituyó una compañía de zarzuela infantil que contó con el beneplácito de la población en general. Así, uno de los concursos realizados por la emisora Ecos de la Montaña de Medellín, para seleccionar talentos artísticos infantiles, fue la base del elenco de la Compañía Juvenil de Revistas y Zarzuelas Frutos de la Montaña.

La compañía, que realizó algunas audiciones para la radio, se centró en el montaje y la representación de las zarzuelas más conocidas del repertorio mundial, obras que se conocían en la ciudad por las compañías extranjeras que actuaron en el teatro principal desde finales del siglo XIX. Aunque Frutos de la Montaña no fue la primera Troupe infantil, si fue la que más temporadas y giras realizó, constituyéndose como la primera empresa de este tipo que se mantuvo en la ciudad por más tiempo ininterrumpido, actúo entre 1939 y 1946. El estudio de la compañía, permite acercarse al acontecer cultural de la ciudad y posibilita desentrañar algunos debates sobre el trabajo infantil, propiciando un acercamiento a las condiciones labores de pequeños artistas, cuya actividad en las representaciones sociales no constituía un trabajo.

Así mismo, la compañía aporta elementos para comprender la aparición de las divas, encarnada en Merceditas Escobar, primera figura de troupe. La reconstrucción de su vida artística, da pistas sobre la intensidad del trabajo actoral y sobre las representaciones de género dentro de la empresa teatral y en general de las que circulaban en la sociedad, además sobre los imaginarios que se tenían acerca de la infancia y la adolescencia. El artículo es una contribución a la historia social, pues se pregunta por las condiciones laborales de los niños en Medellín en una época en que su trabajo y el de las mujeres, hizo posible, en buena parte, la consolidación de la industria antioqueña. También aporta a los estudios sobre el teatro en el país, en los cuales se carece de investigaciones sobre el tema. Pretende además, analizar la participación de Merceditas en la escena artística, desde una perspectiva de género, la cual siguiendo a Scott, es un "[...] elemento constitutivo de las relaciones sociales basadas en las diferencias percibidas entre los sexos y constituye una forma primaria de relaciones significantes de poder"'. De esta manera, la articulación de la historia social, la historia del teatro, la historia de la infancia y el género, ha permitido observar el problema desde diferentes ángulos y ampliar la interpretación a partir de la reflexión de elementos poco estudiados en anteriores investigaciones sobre el tema. El trabajo se apoya, fundamentalmente en los hallazgos hechos en la prensa, en publicaciones periódicas oficiales como Crónica Municipal y no oficiales como

\footnotetext{
${ }^{1}$ Scott, Joan. "El género: una categoría útil para el análisis histórico", en Marta Lamas (comp.). El género: la construcción cultural de la diferencia sexual (México: PUEG, 1996), p. 23.
} 
El Espectador y El Colombiano. Teniendo en cuenta las pocas investigaciones sobre la infancia y la adolescencia que existen en el país. El artículo constituye un aporte fundamental para continuar preguntándose sobre la situación de los niños y de las niñas en diferentes contextos.

\section{Compañías de teatro, ópera y zarzuela en Medellín}

Durante el periodo de existencia del Coliseo o Teatro Principal, construido en 1836 y derribado para dar paso al Teatro Bolívar en 1919, que a su vez se mantuvo en funcionamiento hasta 1954, fecha de su demolición, se presentaron en Medellín más de quinientas compañías de diferentes géneros: drama y comedia, ópera, zarzuela, opereta, danzas y revistas musicales. Entre las compañías que se presentaron en la ciudad es posible establecer diferencias entre las extranjeras -que se dividían en familiares y empresas teatrales-, y las locales ${ }^{2}$. En las compañías familiares predominaban los vínculos de parentesco entre sus integrantes, mientras que las de carácter empresarial albergaban un conjunto de personas entre las que no necesariamente había relaciones de consanguinidad. A diferencia de estas, las compañías locales se creaban por iniciativa de algún artista de la ciudad, que convocaba a aficionados de las artes con el propósito de presentar obras escénicas de distinta índole durante los periodos en que el teatro permanecía desocupado. En ocasiones, las compañías extranjeras incluían actores de la ciudad en su elenco. Además, fue muy frecuente que algunos actores y actrices, al terminar las temporadas, se unieran a nuevas compañías procedentes del exterior o fundaran nuevos colectivos escénicos con los actores locales. Por su parte, las compañías de carácter empresarial, en su mayoría de zarzuela y de ópera, contaban con un empresario, quien reunía el personal y lo llevaba a realizar giras por diferentes países.

En el caso de las compañías locales no resulta exagerado decir que, en la segunda mitad del siglo XIX, la mayoría de ellas fueron lideradas por el vallecaucano Lino Ospina, quien arribó a la ciudad en 1866 para hacer parte de la compañía Isáziga y que terminaría quedándose ${ }^{3}$. Igualmente puede afirmarse que, en las tres primeras décadas del siglo XX estas fueron iniciativas del español Ramón Soler Maymo, quien mantuvo por años el Grupo Escénico. Pese a impulsos como estos, en Medellín, solo hasta la década del sesenta del siglo XX se pensó en el arte dramático como una profesión, idea que se materializó con la creación de la Escuela Municipal del Teatro y el taller de la Universidad de Antioquia ${ }^{4}$.

En cuanto a las compañías infantiles locales, se fundaron varias en la ciudad entre la segunda mitad del siglo XIX y la primera mitad del siglo XX, algunas de ellas dirigidas

\footnotetext{
${ }^{2}$ Para un desarrollo más amplio de la composición y funcionamiento de las compañías de teatro, ópera y zarzuela en la ciudad de Medellín. Correa Serna, Nancy Yohana. Mujeres en escena. De Susana Tirado a Marina Ughetti, (tesis de maestría), Universidad Nacional de Colombia, sede Medellín, 2014.

${ }^{3}$ Marina Lamus Obregón, Teatro siglo XIX. Compañías nacionales y viajeras (Bogotá: Círculo de Lectura Alternativa, 2004), pp. 168-171.

${ }^{4}$ Cristina Toro, "El Teatro en Antioquia", en Historia de Antioquia, Jorge Orlando Melo (Dir.) (Medellín: Suramericana de Seguros, 1991), pp. 463-468.
} 
por el citado Ospina. Si bien, Marina Lamus Obregón afirma que dichas compañías "respondían más a la necesidad de formación de actores desde la temprana edad y no tuvieron los mismos opositores vehementes [que las compañías itinerantes infantiles] porque las circunstancias eran distintas: no se desplazaban, tenían a sus padres cerca y los espectáculos eran más cortos" diferente, pues entre los empresarios el objetivo no fue crear escuelas de actuación como tal y tampoco se suscribieron al territorio local, como es el caso de la Compañía Juvenil de Revistas y Zarzuelas Frutos de la Montaña, objeto del presente artículo. Ni los espectáculos eran más cortos, ni carecieron de oposición de parte de algunos sectores de la sociedad, ni los niños actores tuvieron siempre la cercanía de los padres.

\section{Compañías de Teatro Infantil en Medellín}

En Medellín, a finales del siglo XIX y en la primera mitad del XX, hubo varias iniciativas de artistas para conformar compañías de teatro infantil, a la vez que algunas extranjeras visitaron la ciudad. Si bien, la actividad escénica representaba unas obligaciones laborales y salariales con los niños, nunca se consideró su actividad como un auténtico trabajo; por el contrario, la prensa se encargó de tejer en el imaginario del público que este, antes de ser una obligación penosa para los pequeños artistas, constituía un espacio de diversión y de solaz. La primera compañía de la cual se tiene noticia que contaba con personal infantil, fue la conformada por el español José Marfa en 1871, en la cual se incluyó a una niña identificada como la señorita Molina. La formación de la pequeña actriz estaba a cargo de la señora Marfa y según la prensa: "La señorita Molina, en manos de la señora Marfa, que se ha encargado de su educación escénica, será indudablemente una buena actriz en el desempeño de papeles tiernos, amorosos, sentimentales, porque sus facciones, su mirar, su voz, sus movimientos i candor lo demuestran claramente". En la década siguiente, Lino Ospina y Francisco Vidal fundaron la Compañía Infantil Lírico Dramática, con un elenco en el cual participaron cuatro niñas. Aunque la compañía sumó más cartel que la anterior, su cortas temporadas dejaron al público local con grandes expectativas sobre las representaciones escénicas de los infantes. Desde aquella época, el gusto de los espectadores por la puesta en escena de los niños y de las niñas en la ciudad, tomó fuerza, pues las piezas representadas por estas compañías coincidían con los ideales de moralidad y civilización que las élites culturales y políticas de Medellín habían puesto en marcha desde mediados de siglo XIX.

La ciudad no volvió a ver niños en escena hasta bien entrado el siglo XX, cuando en 1914, por iniciativa del mismo Lino Ospina, se organizó el montaje de algunas obras con una compañía infantil de la cual hacía parte la niña Pola Palacio ${ }^{7}$. Las representaciones se llevaron a cabo en el Salón España y al parecer, no contaron con mucha concurrencia de público, pese a la puesta en escena de la comedia "Juana la Contrabandista" del escritor local Juan José Botero ${ }^{8}$. Cinco años después, debutaba

\footnotetext{
${ }^{5}$ Marina Lamus Obregón, Geografias del teatro en América Latina (Bogotá: Luna Libros, 2010), p. 245.

${ }^{6}$ El Pueblo, Medellín, 26 de abril de 1871, p. 52.

${ }^{7}$ El Colombiano, Medellín, 9 de junio de 1914, p. 3.

${ }^{8}$ El Colombiano, Medellín, 12 junio de 1914, p. 3.
} 
Daniel Restrepo con la Compañía Infantil de Zarzuela, una troupe de la cual se desconoce el elenco, pero que se sabe actuó quebrada arriba ${ }^{9}$, en el barrio Guanteros ${ }^{10}$ y en el Circo Teatro España. Posteriormente arribó a la ciudad la Compañía Infantil Richi, en la cual se anunciaban diez niños en escena ${ }^{11}$, y, en 1915, el ventrílocuo e ilusionista Mr. Víctor M. Karr, ofrecería al público, junto con su espectáculo de magia, los montajes escénicos de una Compañía Infantil que actuaba bajo su dirección ${ }^{12}$.

Con la consolidación de las radiodifusoras en la década del treinta, se llevaron a cabo varios concursos para encontrar talentos infantiles, como fue el caso de la Compañía de Ópera Infantil, dirigida en 1939 por el maestro José María Tena, el cual ofreció unas funciones en el Teatro Bolívar luego de dar a conocer al grupo en el programa de radio denominado La hora infantil, trasmitido por la emisora La Voz de Antioquia. Este tipo de ejercicios dio paso a la conformación del Conjunto Juvenil de Revistas y Zarzuelas Frutos de la Montaña, el cual se mantuvo vigente por siete años y fue escuela de algunas de las principales protagonistas de la escena artística de la ciudad en las décadas siguientes. Compañía de la cual hizo parte Merceditas Escobar, quien comenzó como una actriz y cantante aficionada, pero que con el paso del tiempo y la experiencia adquirida, alcanzó el reconocimiento del público colombiano, no solo por sus puestas en escena, sino también por algunos montajes que subió a las tablas como directora.

Las compañías anteriores, pese a que estuvieron conformadas por niños y por niñas, ofrecían un espectáculo para adultos, pues su repertorio se compuso en la mayoría de los casos, de obras reconocidas por el público local, en el cual no se incluyeron piezas infantiles, género en el que apenas empezaban a incursionar algunos dramaturgos de habla hispana, entre ellos, el español Jacinto Benavente, quien en 1909 emprendió una "campaña de apoyo al teatro para niños, reclamando la existencia de un teatro especializado para ellos y escribiendo varias piezas infantiles: El príncipe que todo lo aprendió en los libros y Ganarse la vida ${ }^{13}$. Aunque de Benavente se pudieron apreciar muchas de sus obras en la ciudad, pues era uno de los dramaturgos favoritos de las compañías de teatro y de los espectadores, nunca se subió a escena ninguna de sus obras escritas para el público infantil.

Lo anterior se debía en parte, a la inexistencia de un público infantil en la ciudad, lo cual respondía a que los niños y las niñas apenas fueron considerados como sujetos de derechos en 1924, con la Primera Declaración de los Derechos del Niño, en la cual se declaró que: "El niño debe ser tratado con todas las consideraciones que aseguren satisfactoriamente su desarrollo físico, psíquico y moral. Debe ser dotado con los medios que le permitan ganar su sustento y debe ser protegido contra la explotación"14.

\footnotetext{
${ }^{9}$ El Espectador, Medellín, 28 de febrero de 1919, p. 2.

${ }^{10}$ El Espectador, Medellín, 15 de marzo de 1919, p. 6.

${ }^{11}$ El Espectador, Medellín, 11 de septiembre de 1919, p. 2.

${ }^{12}$ El Colombiano, Medellín, 26 de noviembre de 1915, p. 3.

${ }^{13}$ Galán, Eduardo. Jacinto Benavente (Madrid: Casals, S.A., 1994), p. 22.

${ }^{14}$ García Londoño, Carlos Edward. Niños trabajadores y vida cotidiana en Medellín (Medellín: Universidad de Antioquia, 1999), p. 93.
} 
La anterior Declaración, apenas fue incorporada en Colombia en la Ley 83 de 1946, denominada Ley Orgánica de la Defensa del Niño, en la cual se creó el Consejo Nacional de Protección Infantil que obligó al Estado a una mayor participación en la protección de los menores ${ }^{15}$.

Así, para los niños y las niñas, apenas se tiene noticia de un espectáculo especializado en 1943, cuando se conformó la Compañía de Cuentos Infantiles "El País de las Maravillas", dirigida por Luis Enrmaun, de la cual no se tiene noticia sobre el elenco. La troupe además de ofrecer un escogido repertorio de piezas infantiles, entre las que se encontraban, "Caperucita Roja”, "Alí Babá y los Cuarenta Ladrones", "Aladino y la Lámpara Maravillosa”, "Pinocho", "Blanca Nieves y los Siete Enanos y "La Cenicienta", donó a la dirección de educación pública de la ciudad, entradas gratuitas para ser repartidas entre los estudiantes de más bajos recursos ${ }^{16}$. Así mismo, el Concejo Municipal destinó una partida presupuestal para la compra de diez mil boletas, “destinadas a los niños de las escuelas públicas del Municipio, las cuales [fueron] distribuidas convenientemente por la Alcaldía y la Fiscalización Escolar". ${ }^{17}$ Los anteriores esfuerzos, contribuían, según la prensa, en encauzar a la niñez de Medellín en espectáculos propicios para su edad, representaciones de "sana moral y bella instrucción", que les ofrecieran otro tipo de actividades, pues: "el niño antioqueño, el de Medellín, nacido y criado sobre bases de cristiandad y alta ética, no encontraba un sitio, una diversión dónde pasar vacaciones, domingos y días de fiesta. Los billares, la vocinglería chocante por las calles, el cafetín -porque hoy en día los niños también van al café- el cine contando historietas de criminales que salen airosos, eran los únicos motivos que hallaban para disipar el tedio dominguero"18.

La preocupación por la inversión del tiempo libre de los niños y de las niñas de Medellín, se había hecho evidente desde principios del siglo XX, cuando gran parte de la población consideraba aceptable el ingreso al mercado laboral de la infancia de sectores marginados; con el argumento de la necesidad de mantenerlos ocupados para evitar que cayeran en la mendicidad, la delincuencia y otras problemáticas vistas como amenazas. Así, la mano de obra infantil, consolidó la producción fabril local, y, los que no engrosaron las listas de trabajadores industriales, recorrieron las calles vendiendo todo tipo de productos. De acuerdo con García Londoño, en Medellín “[...] apoyados en una tradicional ética del trabajo, [...] se publicaron artículos de prensa y otra gran diversidad de escritos en donde se hablaba de las bondades del empleo industrial, de la importancia de la formación técnica y moral que las fábricas les brindaban a la infancia y a la juventud, [...] y, en general de las posibilidades de redención social que ofrecía la industria ante la aguda situación de miseria y desempleo en Medellín"19. Lo anterior demuestra la indiferencia frente al trabajo infantil, que se demuestra en el caso de la Compañía Juvenil de Revistas y Zarzuelas Frutos de la Montaña.

\footnotetext{
${ }^{15}$ García Londoño, Carlos Edward, Op. Cit., p. 94.

${ }^{16}$ El Colombiano, Medellín, 19 de agosto de 1943, p. 2.

${ }^{17}$ Crónica Municipal, Medellín, febrero de 1944, p. 34.

${ }^{18}$ El Colombiano, Medellín, 10 de septiembre de 1943, p. 5.

${ }^{19}$ García Londoño, Carlos Edward, Op. Cit., p. 52.
} 
Para los niños y las niñas que no trabajaban, ni estudiaban, la ciudad tenía dispuestas varias instituciones de beneficencia y caridad, entre ellas, la Sociedad San Vicente de Paúl y sus talleres, en donde se internaron jóvenes entre los seis y los quince años, y, que funcionó entre 1889 y 1910 . La Casa de Menores y la Escuela Titular, que se fundaron en 1914, masculina y femenina respectivamente, y, el Instituto Pedro Justo Berrio que en la década del veinte funcionó como hospicio y escuela para lustrabotas y vagabundos. Dichas instituciones tenían como objetivo, “[...] además de corregir y modificar las costumbres de los internos, capacitar para el trabajo y formar un carácter marcadamente moral en aquellos hijos de los sectores pobres de la ciudad, para que posteriormente trabajaran como artesanos u obreros" 20 .

Pero, Compañía de Cuentos Infantiles El País de las Maravillas, no fue la única iniciativa que tuvo lugar por la década del cuarenta, se tiene noticia de la presentación, en el marco de la Exposición Nacional, llevada a cabo en Medellín en 1944, de la Compañía de Marionetas "Piccoli-Alegria", una propuesta artística patrocinada por el Departamento de Extensión Cultural y Bellas Artes del Ministerio de Educación Nacional, que ofreció en el Teatro de la Exposición, matinées infantiles dedicadas a los niños y a las niñas. ${ }^{21}$ Así mismo, dos años antes, Raúl Ughetti, exintegrante de la conocida compañía de zarzuelas y operetas de Marina Ughetti, patrocinado por el mismo Ministerio, desarrolló una propuesta basada en el teatro móvil, el cual tenía como objetivo hacer una gira nacional en su teatro camión para con su equipo motorizado de marionetas, presentar de manera gratuita espectáculos que educaran en arte y comportamiento al público asistente. En Medellín, el Teatro Pinocho, tal como se conoció, se instaló en la manga de los Puertas, donde asistió diariamente, según la prensa, no menos de tres o cuatro mil personas ${ }^{22}$. A dicho espectáculo, concurrieron cantidades de niños y de niñas que gustaban de la puesta en escena de marionetas.

\section{El funcionamiento de una Compañía de Teatro Infantil: El caso de la Compañía Juvenil de Revistas y Zarzuelas Frutos de la Montaña}

A fines de la década de 1930 el maestro Jaime Santamaría ${ }^{23}$ y Francisco Cuartas, propietario de la emisora Ecos de la Montaña, promovieron un concurso por la radiodifusora para seleccionar talentos artísticos infantiles con el fin de conformar un conjunto juvenil de revistas y zarzuelas, bajo la dirección del citado maestro ${ }^{24}$. Tras la selección, en la cual privilegiaron a pequeños entre los cuatro años y la adolescencia, el equipo se puso a la tarea de ensayar las zarzuelas más recordadas por el público medellinense, las cuales se representarían en los principales teatros de la ciudad. Un

\footnotetext{
${ }^{20}$ García Londoño, Carlos Edward, Op. Cit., p. 61.

${ }^{21}$ El Colombiano, Medellín, 5 de febrero de 1944, p. 6.

${ }^{22}$ El Colombiano, Medellín, 26 de septiembre de 1942, p. 3.

${ }^{23}$ Jaime Santamaría: antes de conformar la Compañía Infantil de Zarzuela y Operetas Frutos de la Montaña, se dedicaba a organizar y dirigir coros polifónicos y conjuntos orquestales. El Colombiano (Medellín) 7 de octubre de 1943, p. 5.

${ }^{24}$ El Colombiano, Medellín, 21 de octubre de 1939, p. 3.
} 
mes después, se anunció el debut de la compañía en el Teatro Bolívar con la zarzuela La Marcha de Cádiz, obra que nunca había sido representada por un elenco infantil autóctono. Dicha presentación se promocionó como un espectáculo familiar que prometía un fin de fiesta a cargo de los más chiquillos de la troupe. Había nacido una nueva compañía, de la que más adelante se afirmó por parte de la prensa, constituyó el primer ensayo formal del teatro colombiano.

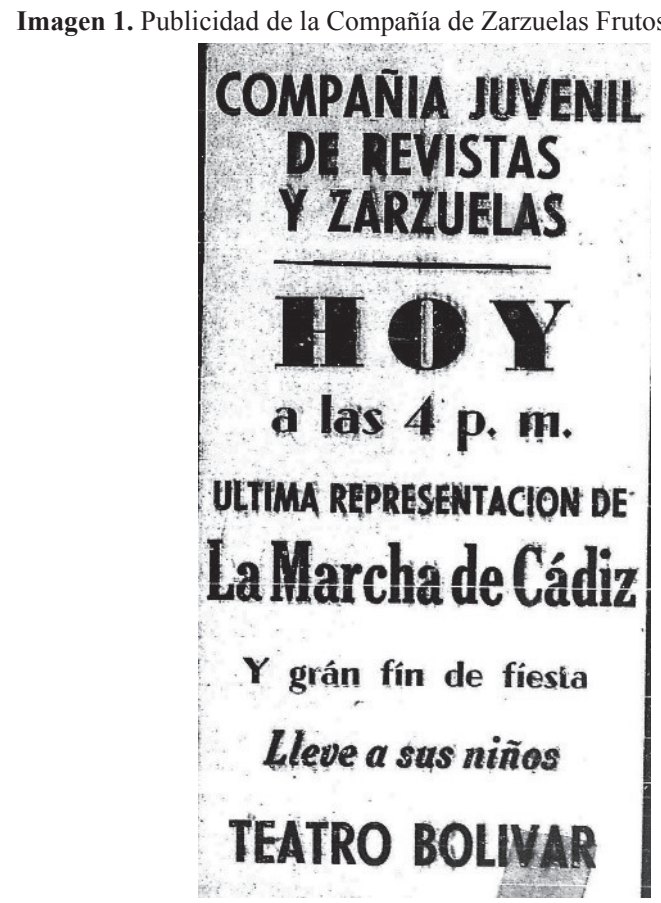

Fuente: El Colombiano (Medellín) 26 de noviembre de 1939, p. 7.

El estreno y demás representaciones fueron todo un éxito; según los diarios, gracias a la disciplina de los artistas a cargo de Santamaría, quien "fue el descubridor y estímulo sin tregua del arte musical"25. Lo que empezó con la representación de una sola zarzuela se extendió durante siete años más, en los cuales los pequeños artistas crecieron jugando a actuar. En 1940, el regreso de la compañía infantil se anunció con un elenco compuesto por treinta y cinco niños, quienes habían ensayado durante el receso entre temporadas, la obra El Puñao de Rosas. Ahora, la compañía había recabado el apoyo de algunas de las más conocidas empresas locales, la Compañía Colombiana de Tabaco, Coltejer, Indulana, Sedeco, Cervecería Unión y Café La Bastilla, quienes contribuyeron con la donación de vestuario y dinero. En esta ocasión, aparte de realizar sus presentaciones en el Teatro Bolívar, los artistas fueron contratados por la empresa Cine Colombia y el Teatro Junín. Lo propio hicieron las autoridades departamentales, que concertaron con la compañía algunas funciones para obsequiar a los estudiantes de planteles públicos en la clausura del año escolar.

${ }^{25}$ El Colombiano, Medellín, 29 de noviembre de 1939, p. 2. 
En 1942, tras tres años de trabajo, y, con el fin de darle continuidad a las labores de la Compañía, Jaime Santamaría gestionaba ante la Asamblea Departamental un auxilio para seguir trabajando, pues el montaje, la producción y la ejecución de las obras eran demasiado costosas. El director, solicitaba una contribución con la imprenta y el ferrocarril para poder publicar los carteles y avisos y, subvencionar los viajes. Sumado a lo anterior, exigía un salario para sí mismo, con el fin de poder dedicarse de lleno a la labor artística con Frutos de la Montaña. Para entonces, lo acompañaba en la conducción escénica la señora Aurora de Alonso, lo cual constituía una novedad en la ciudad, pues durante esta época no se registran mujeres dirigiendo compañías, ya que esta labor se consideró propia de los hombres, razón por la cual el ingreso de las mujeres a este campo se hizo paulatinamente a partir de la segunda mitad del siglo $\mathrm{XX}$, a medida que obtenían preparación profesional en algunos centros educativos de la ciudad. Al parecer, la contratación de la directora escénica, respondió, más que a sus conocimientos en los montajes teatrales, a la capacidad que la sociedad de la época le asignaba como mujer, de cuidar a los pequeños actores y a las pequeñas actrices.

Así pues, Con el apoyo de la empresa privada y de las entidades públicas, los resultados pecuniarios comenzaron a palparse, así que los pequeños artistas no pararon de trabajar. No tardó mucho el público en reconocer las aptitudes escénicas de algunos de los elementos de la compañía, entre ellos, se consolidó como actriz, cantante y bailarina, la niña Merceditas Escobar, quien se convertiría en la primera figura y en el eje central de la troupe. Tal fue la fama que la acompañó y la importancia que alcanzó en Frutos de la Montaña, que logró consolidar una carrera artística independiente, la cual la alejó en varias ocasiones de su original compañía. Así, en 1943, mientras trabajaba en Bogotá, Santamaría reforzó el elenco con la bailarina clásica bogotana Marina Vásquez, quien se sumó a la empresa para dinamizar los actos de variedades que se ejecutaban al final de las representaciones teatrales, debido a la ausencia de la pequeña diva Escobar.

Entre números de baile, de humor y de canto, los actos de variedades constituían uno de los programas más importantes para este tipo de compañías, pues era el espacio en el cual los infantes podían brillar de manera individual y mostrar al público sus capacidades en el arte que mejor se desempeñaran. Con el reintegro de Merceditas al elenco tras su actuación en la Capital de la República, fue indudable que la compañía emprendió con más entusiasmo los nuevos proyectos, así lo expresaron los cronistas culturales de la ciudad, quienes veían en ella una joven caracterizada por "la gracia precozmente femenina y el protuberante temperamento artístico"26, el que según ellos no poseían todos los niños del conjunto.

A su llegada, la compañía volvió a las tablas con un estreno; la zarzuela 'La Viejecita', en la cual Merceditas interpretaba el papel principal. Esta obra, en la que el director invirtió cerca de setecientos pesos en vestidos y decorados, se promocionó primero por la emisora "La Voz de Antioquia"27, en donde los artistas la interpretaron para los amantes del radioteatro. Luego debutaron en el Teatro Junín, representaciones en las

\footnotetext{
${ }^{26}$ El Colombiano, Medellín, 10 de marzo de 1943, p. 5.

${ }^{27}$ El Colombiano, Medellín, 27 de mayo de 1943, p. 12.
} 
que fueron acompañados en la parte musical por el maestro Fernández Caballero y en la dirección escénica por Carmen de Granados, convirtiéndose en la segunda mujer que ocupaba este cargo en esta compañía.

De esta manera, en los primeros años de funcionamiento de la compañía, el apoyo de las empresas privadas y de las entidades públicas, fue fundamental para darle continuidad al proyecto artístico de Santamaría. Si bien, desde principios del siglo XX, las compañías extranjeras, le solicitaban al Concejo Municipal exención de impuestos y apoyo económico, y, al Ferrocarril de Antioquia, la disminución en fletes para el personal y los equipajes ${ }^{28}$, Frutos de la Montaña por su calidad de compañía local y por estar integrada por niños, niñas y jóvenes, fue eximida por parte de Concejo del pago de impuestos en las temporadas de $1941^{29}$, de $1943^{30}$ y de $1945^{31}$. Por su parte, la empresa privada extendió su proyecto cultural a Frutos de la Montaña, una apuesta que demostraba los gustos y la sensibilidad de una burguesía industrial con capacidad de masificar sus representaciones particulares de la sociedad. Lo que empezó con el patrocinio de programas radiales educativos en las principales radiodifusoras de la ciudad, como el "Teatro del Aire"; dirigida por Marina Ughetti y financiada por la Compañía Colombiana de Tabaco ${ }^{32}$, el "Teatro en Casa" de Fabricato ${ }^{33}$ y los conciertos Coca Cola ${ }^{34}$, se desplazó a las tablas.

\section{Las giras}

La primera gira artística, la llevaron a cabo en enero de 1941 por los departamentos de Caldas y Valle del Cauca, la cual contó con apoyo de la Gobernación de Antioquia, la Alcaldía de Medellín y las principales casas comerciales de la ciudad ${ }^{35}$. En el elenco se distinguían las niñas Merceditas Escobar, Luzmila Gaviria, Luz Jaramillo, Ligia Ramírez, Ofelia Cardeño, Carmen Riera, Betty Betancourt y la bailarina Hortensia Echavarría. Entre los niños figuraban Hernán Palacios, Jorge Ochoa, Jairo Correa, Jorge Burgos, Augusto Zuleta y Luis Restrepo. Acompañando a los pequeños artistas también viajaron algunas señoras, según la prensa, muy distinguidas, quienes, junto al maestro Santamaría, estuvieron a cargo de todo lo concerniente con la pueril compañía ${ }^{36}$. Las actividades de las acompañantes se centraban en el cuidado de todos los niños, a los cuales se les debía garantizar una adecuada atención que incluía consolarlos cuando las horas de trabajo y de ensayo los agobiaban debido a su escasa edad, una extensión del trabajo doméstico en la compañía, que no incluía actividades intelectuales ni de creación. En la mayoría de las ocasiones, no viajaron

28 Nancy Yohana Correa Serna, “Teatro y Sociedad en Medellín 1880-1910”, (tesis de pregrado), Universidad de Antioquia, 2004), pp. 76-84.

${ }^{29}$ Crónica Municipal, Medellín, 1 de noviembre de 1941, p. 6231.

${ }^{30}$ Crónica Municipal, Medellín, julio de 1943, p. 6842.

${ }^{31}$ Crónica Municipal, Medellín, febrero de 1945, p. 11.

${ }^{32}$ El Colombiano, Medellín, 2 de mayo de 1937, p. 3.

${ }^{33}$ El Colombiano, Medellín, 16 de enero de 1948, p. 4.

${ }^{34}$ El Colombiano, Medellín, 4 de marzo de 1944, p. 6.

${ }^{35}$ El Colombiano, Medellín, 8 de diciembre de 1940: 4. La gobernación y la alcaldía apoyaron a la compañía con mil pesos, las casas comerciales con novecientos pesos y las empresas textiles con telas para el vestuario.

${ }^{36}$ El Colombiano, Medellín, 8 de enero de 1941, p. 7. 
Compañias de teatro y trabajo infantil en Medellín. El caso de Merceditas Escobar en Frutos...

con sus familiares, razón por la cual, se asemejaban más al tipo de compañías infantiles extranjeras, en las cuales los y las infantes eran organizados alrededor de un empresario.

Finalizando el año, el ritmo de trabajo no disminuyó y para cerrar con éxito rotundo, el gerente Emilio Franco firmó un contrato especial con Cine Colombia para trabajar dos días en el Teatro Colombia y ocho en el Teatro Roxy de Bogotá. Así mismo, concertó una gira por Tunja, Pamplona y Bucaramanga, en donde se convirtieron en ídolos de niños y niñas, y, continuaron en Cúcuta, para emprender su primer viaje internacional, a ciudades limítrofes de Venezuela, entre ellas San Cristóbal en el Estado de Táchira ${ }^{37}$. Para esta gira, el conjunto había crecido, dos nuevos directores de escena se estrenaron, Jesús Escobar y Gabriel Palacios, además los acompañaban las damas Gabriela Santamaría, Concha Santamaría de Torres, Esther de Santamaría y doña Inés Berrío de Gaviria ${ }^{38}$, las tres primeras al parecer familiares del director general.

En enero de 1942 reanudaron labores en el Teatro Bolívar, poniendo de nuevo en escena las zarzuelas "La Alegría de la Huerta", "Los Gavilanes", "Banda de Trompetas", "El Rey que Rabió" y las obras colombianas "El Grito de la Raza" y "El Sueño de la Abuelita". Al terminar las funciones, ofrecieron una representación en el Salón del Patronato de Obreras a beneficio de las obras de esta reconocida institución, que proveía dormitorios y otros servicios a trabajadoras jóvenes solteras e inmigrantes sin familia en la ciudad. Las funciones de beneficio, fueron comunes entre todas las compañías de teatro que se presentaron en Medellín desde el siglo XIX, dichas representaciones les otorgaba la admiración del público y, contribuía, a mejorar la asistencia del mismo a las demás funciones programadas durante las temporadas.

Imagen 2. Publicidad de la Compañía de Zarzuela Frutos de la Montaña

\section{LA GRAN COMPANIA INFANTIL FEUTOS DE LA MOTENANA Estrenará el Sábado de Glêria el Salén del Patronato de Obreras, situado en la Plaza de Flórez, con la her-
mosa opereta:}

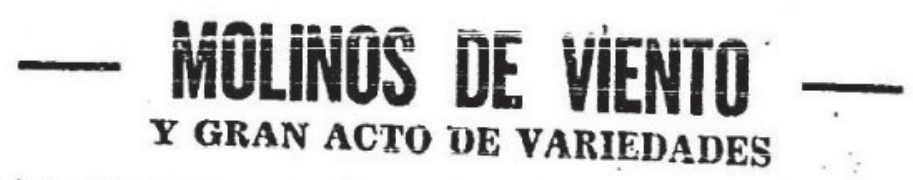

Estas funciones serán a beneficio de las obras del
Patronato.

PRECTOS: UNICA ENTRADA, \$ 0-5n

NO OLVIDE USTED: Sábado 4 de $\Lambda$ bril, a las $81 / 2$ p. m.

Fuente: El Colombiano, Medellín, 1 de abril de 1942, p. 12.

\footnotetext{
${ }^{37}$ El Colombiano, Medellín, 9 de noviembre de 1941, p. 11.

${ }^{38}$ El Colombiano, Medellín, 9 de septiembre de 1941, p. 2.
} 
Así mismo, la compañía ofreció diversas presentaciones en los Coliseos de distintos municipios antioqueños como Yarumal, donde fue invitada para inaugurar el teatro "Coliseo" de dicha ciudad, ${ }^{39}$ Santa Rosa de Osos, Támesis, Sopetrán, Fredonia, Caramanta, Itagüí y Caldas. En 1943, la Compañía comenzó otra gran gira, esta vez por el occidente colombiano, con el fin de trabajar en los teatros de Bolívar (Antioquia), Anserma (Caldas), Riosucio (Caldas), Manizales (Caldas), Pereira (Risaralda), Armenia (Quindío), Sevilla (Valle del Cauca) y Cartago (Valle del Cauca). Dos años más tarde, luego de un receso de actividades de la actriz principal de la compañía, Merceditas Escobar, la compañía fue incluida por la dirección de extensión cultural del Ministerio de Educación en el escalafón artístico, lo cual representaba para el conjunto poder recorrer el país sin obstáculos y contar con el apoyo oficial de manera más decidida ${ }^{40}$.

Entre tanto, con el sostén del gobierno local y por invitación de las entidades cívicas, culturales y administrativas de algunos municipios del departamento, emprendieron una nueva gira, que los llevó hasta Bogotá, en donde trabajaron en el Teatro Lux, el cual había sido cedido por Cine Colombia tras varios trámites del director Jaime Santamaría, quien también aprovechó la visita capital para “[...] gestionar con las entidades oficiales, especialmente con la sección cultural y artística del Ministerio de Educación Nacional, el auspicio económico para la realización de esta temporada y el apoyo para las representaciones de la misma durante la celebración de la exposición de Interamericana"41 que se desarrollaría en aquella ciudad en 1946. Durante la temporada recibieron muy buenos comentarios por su trabajo. El diario El Colombiano, publicó una opinión sobre la troupe divulgada en el periódico El Espectador que decía lo siguiente: "Frutos de la Montaña conquista desde el primer momento, porque está formada con valores de excepcional comprensión y porque no hay un solo detalle que disuene" ${ }^{42}$. Fue tanto el éxito alcanzado en la capital, que los invitaron a presentarse en el Teatro de la Media Torta, un teatro al aire libre inaugurado desde 1938, que se había convertido en el principal centro de la cultura popular y en donde los pequeños artistas engalanaron el programa organizado por el Ministerio de Educación Nacional ${ }^{43}$.

La última correría de la compañía por Bogotá, fue todo un éxito, pues realizaron una audición privada en el Palacio de la Carrera para el Presidente de la República, Mariano Ospina Pérez y su esposa Berta Hernández Fernández. Pese al éxito obtenido, días después de la llegada a la ciudad de Medellín, el maestro Jaime Santamaría anunció por los medios de comunicación su decisión de retirarse de la dirección de la compañía; el motivo de la determinación, al parecer fue el cansancio y unos compromisos pedagógicos que había adquirido. Para la despedida, se organizaron algunas funciones en honor del maestro, se anunció que se estrenarían más de treinta números de variedades, la mayoría dirigidos por Merceditas. Así pues, con la opereta

\footnotetext{
${ }^{39}$ El Colombiano, Medellín, 23 de marzo de 1942, p. 3.

${ }^{40}$ El Colombiano, Medellín, 28 de abril de 1945, p. 9.

${ }^{41}$ El Colombiano, Medellín, 16 de septiembre de 1945, p. 2.

${ }^{42}$ El Colombiano, Medellín, 18 de octubre de 1945, p. 3.

${ }^{43}$ El Colombiano, Medellín, 20 de octubre de 1945, p. 3.
} 
"La Princesa de las Czardas", le dijo adiós a los escenarios la compañía infantil Frutos de la Montaña, escuela de artistas por más de siete años. El 1 de diciembre de 1946, se presentó por última vez en el Teatro Junín la compañía infantil y diez días después se anunciaba el homenaje que la ciudad le rendiría a Merceditas Escobar.

\section{Merceditas Escobar}

Al regreso de la primera correría, Merceditas Escobar se había destacado entre los principales elementos del conjunto, la prensa afirmaba que era "la primera estrella, con perfil tan neto y fuerte, que desde el primer instante de la representación se destaca". ${ }^{44}$ Su carrera artística iniciaba su ascenso y ella parecía ser consciente de ello, puesto que al volver al proscenio, esta vez en el Instituto Central Femenino, interpretó lucidamente su personaje ante las estudiantes del plantel y los invitados especiales, entre los que se encontraban algunos diputados de la Asamblea Departamental y las damas pertenecientes al Cuadro de Honor de la Sociedad de Mejoras Públicas de Medellín. ${ }^{45}$ Merceditas, convertida en la preferida del público, había nacido el 13 de octubre de 1930 en el municipio de Cañasgordas (Antioquia); su padre, Jesús Escobar, oriundo de Santa Fe de Antioquia y amante del teatro, fue quien le enseñó a cantar, ${ }^{46}$ y su primera experiencia como cantante la obtuvo al lado del maestro José María $\mathrm{Tena}^{47}$ en los coros infantiles de la radiodifusora "La Voz de Antioquia que emitía un programa denominado "La Hora Infantil"48. De allí, ganadora de un concurso promocionado por la emisora, fue al Teatro Bolívar a cantar "Noche de Ronda". Hablar en adelante de Merceditas, es referirse a la compañía escénica infantil Frutos de la Montaña, conjunto teatral en el cual consolidó su carrera artística.

La figura de Merceditas Escobar, se destacó entre las demás niñas de la compañía, al punto que fue contratada de manera individual para trabajar en uno de los clubes de moda de Medellín de la década del cuarenta, el Covadonga. Allí, a mediados de 1942, compartió escenario con el reconocido humorista Mario Jaramillo, con quien ejecutó algunas danzas y recitó apartados de las obras que más reconocimiento le habían merecido. La prensa manifestó aprecio y admiración por la joven artista con palabras poéticas: "Jamás la armonía se llamó con su nombre de cristal, jamás la música tuvo esa edad de rosa y de libélula/Y cuándo las canciones fueron niñas, tan niñas como ella, como sus manos donde apenas puede soñar la nieve?/Y cuándo el ritmo tuvo tanta maravillosa geometría? Leve, levísima, cruza con el trino, apenas con la sombra de unas alas que hacen, más luz que sombra"49. Para entonces el reconocimiento de su talento en la ciudad, se había forjado no solo en la compañía infantil, sino también en numerosas presentaciones como solista en escenarios

\footnotetext{
${ }^{44}$ El Colombiano, Medellín, 15 de marzo de 1941, p. 5.

${ }^{45}$ El Colombiano, Medellín, 6 de mayo de 1941, p. 3.

${ }^{46}$ El Colombiano, Medellín, 19 de agosto de 1941, p. 3.

${ }^{47}$ El maestro José María Tena, de origen español, había arribado a la ciudad en 1935 con la Compañía de Zarzuelas de Marina Ughetti. Tras la disolución de la troupe, Tena inició labores con la emisora La Voz de Antioquia.

${ }^{48}$ El Colombiano, Medellín, 9 de noviembre de 1942, p. 5.

${ }^{49}$ El Colombiano, Medellín, 11 de junio de 1942, p. 2.
} 
diferentes a los teatros principales, razón por la cual, fue contratada para trabajar durante una temporada en la ciudad de Bogotá.

Escobar se estrenó en la capital en el Teatro Municipal con la compañía Estampas Líricas, una troupe infantil que había sido fundada en dicha ciudad por el maestro italiano Ricci y su esposa Aida, a imitación de la experiencia y éxitos de Frutos de la Montaña. En su primera representación, la acompañó la colonia antioqueña residente en la capital, quienes después de su debut enviaron al periódico El Colombiano el siguiente mensaje telegráfico: "Grandioso éxito Merceditas Escobar en debut hoy. Colonia Antioqueña" 50 . Al finalizar la temporada, volvió a Medellín a pasar con su familia las fiestas de fin de año y fue tratada como toda una vedette, pues a su arribo se le realizó un interviú en el cual aseguró que durante su estancia en Bogotá solamente se dedicó a trabajar. Pese a su corta edad, esta niña llevaba varios años en el escenario, sus días transcurrían en las tablas, rodeada de telones y de toda la indumentaria necesaria para el montaje de las obras, sin embargo añoraba los juegos propios de la niñez y le confesó al reportero, cuando este le preguntó por los aguinaldos, lo siguiente: "Si viera la muñeca que me regalaron. Tiene la propiedad de dormirse cuando uno la acuesta y cuenta con todo un vestuario completo. Yo tengo un lindo muñequero, cuando quiera ir a mi casa lo invito con mucho gusto para que lo vea... Es lo único, con la ausencia de mi casa, que me fastidia en Bogotá y es que no me dejan jugar con mis muñecas, llevarlas de paseo, cortarles sus vestidos, y hacer las fiestas que aquí hacía con mis amiguitas". ${ }^{51}$ Con sus afirmaciones Merceditas dejaba claro que aún era una niña y que no bastaba con jugar a ser actriz, que lejos de ser un juego, la actividad de las tablas le exigía largas horas de estudio y no daba cabida al disfrute de las actividades de ocio infantil que más le atraían.

Tal como lo evidencia Escobar, ser actriz implicaba un esfuerzo físico; lo que para el público en general era visto como diversión; pero esto no era así para los actores infantiles, toda vez que el montaje de las obras requería largas horas de ensayo y por lo regular, las funciones tenían lugar en la noche. Al parecer, los empresarios teatrales no contemplaban la Ley 9 de 1930, en la cual se reafirmaba la prohibición de contratar menores de 14 años en trabajos inadecuados o sin la presentación del certificado de mínima educación, que se había sancionado en la Ley 56 de $1927^{52}$. Merceditas había sido contratada desde muy niña y, a su llegada a Bogotá, apenas contaba con 12 años. A pesar de que los empresarios y la sociedad en general, veían con buenos ojos la participación de niños y niñas en los escenarios, para los y las infantes el trabajo artístico en muchas ocasiones era pesado para su edad, es decir, inadecuado, a lo que se suma que la mayoría de artistas apenas cursaban estudios en la ciudad.

En enero de 1943, Merceditas se reintegró a la troupe; con quienes inició labores en el mes de febrero. Al terminar las representaciones, la joven cantatriz realizó una gira por Venezuela, la cual la motivó a continuar con sus estudios artísticos y a superarse

\footnotetext{
${ }^{50}$ El Colombiano, Medellín, 6 de noviembre de 1942, p. 2.

${ }^{51}$ El Colombiano, Medellín, 23 de diciembre de 1942, p. 2.

${ }^{52}$ García Londoño, Carlos Edward, Op. Cit., p. 94.
} 
cada vez más en su profesión como actriz y cantante. A su llegada, emprendió una tour por el occidente de Antioquia, en la cual estuvo acompañada por su madre. El primer municipio que visitó fue Santafé de Antioquia, en donde ofreció dos veladas artísticas, las cuales fueron organizadas por las damas del Club Noel de Antioquia con el fin de recaudar fondos para la estatua en bronce del recién fallecido obispo Francisco Cristóbal Toro Correa. Durante esta correría, visitó también los municipios de Cañasgordas y Frontino ${ }^{53}$. En su visita a Cañasgordas, fue recibida por gran cantidad de población, quienes la ovacionaron y la invitaron a desfilar por las principales calles acompañada de niñas y niños. Tras su presentación en el teatro parroquial, grupos de damas y de caballeros la acompañaron hasta la casa de sus familiares, lugar donde se hospedó. Al amanecer recibió una serenata por parte de una orquesta de la localidad y unos jóvenes pusieron en su casa una placa con la siguiente inscripción: "Aquí nació Merceditas Escobar"54.

Luego de su arribo a Medellín y de rodar por el occidente colombiano con la compañía, Merceditas se despidió del público, ya que su familia decidió retirarla un tiempo de las tablas por recomendación médica, pues ya rondaba los límites de la niñez. Tras el anuncio del cese de actividades escénicas, respondió a una entrevista, en la cual volvió a aseverar como años atrás que deseaba convertirse en actriz de cine, confesó que admiraba a la actriz y cantante canadiense Diana Durbin y que durante su receso se dedicaría a estudiar para sorprender al público cuando volviera al proscenio ${ }^{55}$. Al año siguiente se realizó en el Teatro Junín una velada en honor a Merceditas Escobar, por su retiro de la vida artística, debido a su edad y a su crecimiento físico, era ya una señorita que a lado de sus compañeros de escena, empezaba a parecer una adolescente, según su médico, durante esta transición de niña a mujer era mejor que estuviera alejada de los escenarios. La obra escogida para la gala fue La Viejecita, en la cual Merceditas personificaba a una anciana muy apreciada por el público, durante su ejecución se le entregó a la artista un pergamino por parte de sus compañeros de escena con las firmas de los directores y artistas, el cual fue la muestra del aprecio y la gratitud que le profesaban a la actriz ${ }^{56}$. La apertura de la función, estuvo a cargo del columnista del periódico El Colombiano Juan Roca Lemus, más conocido como Rubayata, en el discurso se exaltó la capacidad de Antioquia para producir espectáculos como el proporcionado por una compañía infantil compuesta por niños y niñas locales, quienes lograron montar obras del repertorio internacional, hasta la fecha solo interpretadas por compañías con una amplia experiencia. Sobre Merceditas Escobar, leyó que "[...] su nombre lo han llevado los vientos, como una lanzadera de emociones doradas para coser las armonías de toda la república. Su nombre ha sido un SESAMO para abrir todos los portalones seccionales. Y desde cuando principiaba a espigar y a balbucir canciones, se dio el lujo de verse seguida de muchedumbres, que fueron su cauda sensacional y al mismo tiempo la cauda nacional de esta Antioquia relampagueante y preclara"57.

\footnotetext{
${ }^{53}$ El Colombiano, Medellín, 3 de julio de 1943, p. 2.

${ }^{54}$ El Colombiano, Medellín, 24 de agosto de 1943, p. 2.

${ }^{55}$ El Colombiano, Medellín, 4 de septiembre de 1943, p. 7.

${ }^{56}$ El Colombiano, Medellín, 20 de enero de 1944, p. 12.

${ }^{57}$ El Colombiano, Medellín, 23 de febrero de 1944, p. 7.
} 
El caso de Merceditas, fue único en la compañía y refleja las representaciones sobre las mujeres que se tenían en la ciudad. Si bien, una de las razones por las cuales el público local apreciaba este tipo de troupe, era la condición asexuada que le conferían a sus integrantes por la edad, una vez llegado el límite de la niñez, tomaban forma las representaciones de género, estereotipos que habían funcionado desde el siglo XIX, en el cual se restringía a la mujer a un rol reproductivo y de cuidado del hogar, que no permitió consolidar la profesión de actriz en la ciudad, en la cual, desde el siglo XIX hasta mediados del siglo XX, apenas tres mujeres optaron por las tablas como oficio: Susana Tirado, Carlota Uribe y Clarisa Márquez Yepes ${ }^{58}$.

Merceditas estuvo de vuelta en las tablas, para la temporada de 1945 con las habituales zarzuelas de su repertorio, pero con un nuevo programa de variedades, pues la vedette infantil sorprendió al público con números de flamenco, baile que le mereció que la compararan con la famosa actriz María Antinea ${ }^{59}$, pues compartían según la prensa, "gracia, salero y verdad raciales"60. Su cumpleaños número 15 , lo recibió en medio de una gira por la ciudad de Bogotá, por tal motivo la prensa local publicó un poema escrito por Calixto Ibañez Díaz en honor de la reconocida actriz, del cual se recogen algunos versos:

Es Mercedes Escobar

Una flor de Andalucía

Que brotó en Antioquia un día

Por milagro singular.

La fama estrenó trompeta

Cuando se meció su cuna, Y la besó la Fortuna, Por su Destino sujeta.

Ahora, yo, que soy poeta, Mi lira quiero pulsar

$\mathrm{Y}$, ante el mundo, declarar

Que, de todo el universo,

Lo que más provoca al verso

Es Mercedes Escobar.

Siendo Flor de la Montaña,

De la montaña antioqueña,

Se mostró, desde pequeña,

Auténtica Flor de España.

Una bendición extraña,

Que todo pueblo, querría,

A Antioquia bajó en el día

En que Mercedes nació

Y, a su vergel, agregó

Una Flor de Andalucía [... $]^{61}$.

\footnotetext{
${ }^{58}$ Correa Serna, Op. Cit., pp. 85-138.

${ }^{59}$ Actriz y bailarina española que visitó la ciudad en dos ocasiones, en 1944 y en 1946.

${ }^{60}$ El Colombiano, Medellín, 18 de abril de 1945, p. 4.

${ }^{61}$ El Colombiano, Medellín, 28 de octubre de 1945, p. 7.
} 
Este poema, como muchos otros comentarios que se escribieron de la actriz, hacían referencia a sus dotes artísticas, los cuales compararon constantemente con otras artistas españolas, pues el fuerte de Merceditas fue el flamenco. Lo interesante de las opiniones sobre las capacidades en escena de Escobar, es que hicieron hincapié en la herencia española, de la cual según los periodistas había adquirido lo más exquisito. Debido a que Merceditas había cumplido quince años en Bogotá, no se le había homenajeado correctamente por parte del público de la ciudad de Medellín, así que en una de las columnas de El Colombiano, el periodista Jorge Robledo Ortiz, escribió unas palabras para la actriz, en las que resaltó su talento y sus grandes capacidades para interpretar tonadillas españolas y bailar como toda una gitana, según Ortiz:

\begin{abstract}
Verla y oírla en su caracterización de bailaora, es asistir a una fiesta de folklore gitano: el mantón de Manila recortado sobre la albura de los hombros; traje de colores vivos, con tendencia al clavel y al heliotropo; la falda en anchos revuelos campanudos; una rosa sobre la reluciente seda del cabello; los labios siempre florecidos de reir; las castañuelas acompasando el rítmico movimiento de los pies; y las soleares o las seguidillas, brotando de su garganta como un pentagrama de cristal $^{62}$.
\end{abstract}

En 1946, Merceditas ofreció su primera presentación junto con el trío aguadeño de los Hermanos Hernández, quienes desde la década del treinta se venían consolidando como un conjunto musical en la escena cultural de Medellín. El representante artístico de Merceditas, convino un contrato con el trío para terminar la temporada que estos llevaban a cabo en el Teatro Bolívar. Una de las primeras revistas en las que actuaron juntos, fue la denominada Si yo fuera Presidente, allí trabajó con los Hernández y la pareja de artistas Rubians-Tirana, esta última le entregó a Merceditas en una de las funciones una caja de orquídeas que le fue enviada por sus admiradores del público ${ }^{63}$. Así mismo, subieron a escena La Revista Local, en la cual participaron las hermanas Riera, compañeras de Escobar en Frutos de la Montaña. Para esta época, Merceditas ya contaba con un representante artístico, agente del cual solo disponían las artistas más importantes de la época, lo que indica el ascenso de la carrera de la pequeña actriz en tan poco tiempo.

A mediados de año, la compañía infantil debutó en el Teatro Junín con la opereta "El Soldado de Chocolate", la cual dirigió el barítono, recitador teatral y escritor José María Pineda, quien ya había trabajado con la troupe. También, montaron algunos actos de variedades nuevos, entre ellos, el cuadro de Francisco Montes, el cual dirigió Merceditas Escobar y que estaba basado en un paso doble que fue ejecutado por algunas parejas de la agrupación. ${ }^{64}$ Este fue el segundo programa que dirigió Merceditas en su carrera artística, el estudio, la disciplina y la creatividad de la actriz, la tenían en lo más alto de la escena, la dirección. Toda la producción de la temporada fue patrocinada por el Ministerio de Educación Nacional, la Asamblea Departamental y el Municipio de Medellín, lo que garantizó un éxito rotundo, pues el programa fue

\footnotetext{
${ }^{62}$ El Colombiano, Medellín, 9 de diciembre de 1945, p. 7.

${ }^{63}$ El Colombiano, Medellín, 2 de abril de 1946, p. 5.

${ }^{64}$ El Colombiano, Medellín, 27 de junio de 1946, p. 2.
} 
repetido varias veces. Meses después volvieron al Teatro Bolívar, subieron a escena una opereta de Kalman y Merceditas presentó sus últimas creaciones, dos cuadros de ambiente español titulados: “'Antonio Vargas Heredia', en el que se simula[ba], con bellas canciones dialogadas, una corrida de toros como se estilan en los más afamados centros taurinos de España; y 'Luna enamorada', también del más puro sabor español" ${ }^{65}$. El primer cuadro fue escrito para Merceditas por un reconocido periodista local. Antes de finalizar la temporada y partir con destino a la ciudad de Bogotá, subieron a las tablas "Molinos de Viento" y "Soldado de Chocolate", obras con la cuales habían agradado al público en representaciones pasadas.

Tras la disolución de la compañía en 1946, se organizó un homenaje de despedida en honor a la actriz. En él tomaron parte artistas locales de radio y de teatro, entre ellos, Las Maiceritas, Fortich y Valencia, Amparo y Lucía, Enrique Botero, Nelly y Gildardo, Jaime Hernández, Antonio Ochoa, Rosarito Escobar, el humorista Mario Jaramillo como animador y la presentación de la actriz estuvo a cargo de Juan Roca Lemus, Rubayata. Por su parte, la artista ofreció un programa en el cual incluyó sus números de flamenco que más apreciaba el público. Fue tan concurrido el acto, que se repitió al día siguiente.

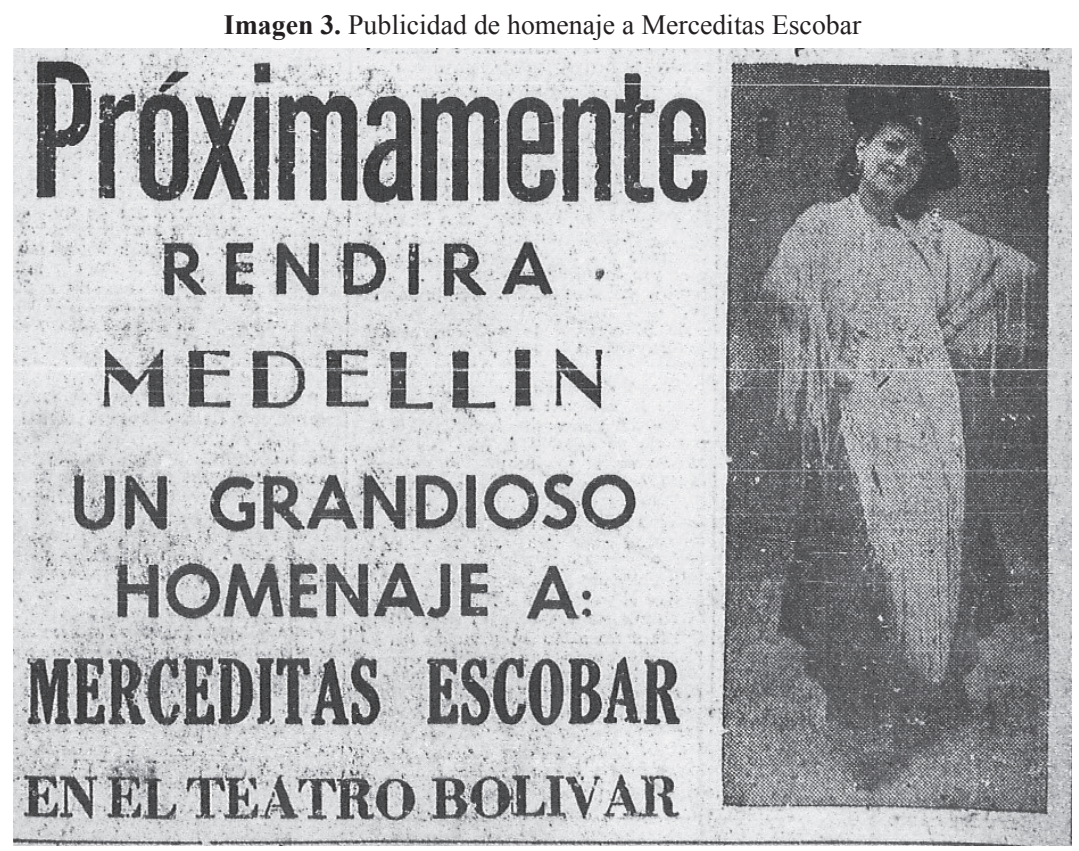

Fuente: El Colombiano, Medellín, 10 de diciembre de 1946, p. 16.

En marzo de 1947, se supo que Merceditas estaba estudiando en el colegio de las carmelitas en Medellín y que asistía a la academia cinematográfica dirigida por Enrique Peña Franco, auspiciada por el empresario Félix Restrepo. Meses después, se

${ }^{65}$ El Colombiano, Medellín, 24 de agosto de 1946, p. 5. 
interesó por convertirse en la embajadora cultural del país en las principales naciones latinoamericanas y como homenaje en el mes de las madres, volvió al Teatro Bolívar para actuar, cantar y bailar en una velada artística ${ }^{66}$. En junio, anunció su despedida de la ciudad con un programa combinado con cine; decidió entonces poner en marcha su proyecto de llevar el nombre de Antioquia y de Colombia, por los principales escenarios nacionales e internacionales, empezando por una gira al interior del país para continuar en Venezuela. A su llegada en el mes de octubre, se unió al elenco del humorista Carlos Emilio Campos, Campitos, con quien actuó en las últimas funciones de la temporada y después se alistó en la Compañía Nacional de Comedias y Variedades para trabajar en la gira que emprendieron por el suroeste antioqueño. De Merceditas solo se volvió a tener noticia hasta 1996, cuando el periodista Luis Eduardo Muñoz Álvarez, indagó por la suerte de la cantante antioqueña, de la que le informaron se encontraba radicada en Cúcuta donde poseía una joyería llamada El dije de plata ${ }^{67}$. Allí contrajo matrimonio y se retiró de las tablas, aunque nunca dejó las artes, pues se dedicó a la pintura y a la escritura de poemas hasta el día de su fallecimiento, el 24 de noviembre del 2015.

\section{Trabajo o vocación artística}

Los directores de Frutos de la Montaña, recibieron diversas cartas de espectadores en las que los felicitaban por su encomiable labor y los instaban a seguir trabajando por el cultivo del arte en los niños y las niñas. Entre las manifestaciones de entusiasmo podía encontrarse una nota del profesor de música bogotano, Eliseo Hernández, quien les hizo un reconocimiento con las siguientes palabras: "Se ve el enorme trabajo de ustedes hasta el más leve detalle y encanta la facilidad con que los primorosos niños hacen interpretaciones que satisfacen plenamente porque sería imposible exigir más a tan diminutos artistas. Este trabajo es digno de todo elogio por tratarse de un grupo enteramente criollo y en mi concepto ustedes merecen un apoyo de los gobiernos departamentales por donde viajan..." ${ }^{96}$. Numerosos comentarios reiteraban la importancia de consolidar procesos artísticos autóctonos, así como la creación de un verdadero teatro nacional, esfuerzos que se venían haciendo en Medellín desde el siglo XIX con el vallecaucano Lino Ospina y en la segunda década del siglo XX con el Grupo Escénico.

El patrocinio del gobierno local y de algunas empresas, permitió a la compañía abordar nuevos montajes y nuevas giras nacionales. Esto, sumado a la disciplina de los artistas, quienes para la prensa, "se revelaban ya como artistas de nota, con vocación para la escena, dueños de sí mismos, interiormente controlados, espiritualmente disciplinados, sometidos a un reglamento que no se ha escrito pero que cada uno lleva consigo para obedecerlo" "69, constituyó toda un éxito en el proscenio. Con dicho apoyo se consolidó la empresa, mientras que, entre los ensayos, las giras y las representaciones locales,

\footnotetext{
${ }^{66}$ El Colombiano, Medellín, 10 de mayo de 1947, p. 14.

${ }^{67}$ El Colombiano, Medellín, 9 de diciembre de 1996, p. 14c.

${ }^{68}$ El Colombiano, Medellín, 16 de abril de 1941, p. 11.

${ }^{69}$ El Colombiano, Medellín, 15 de agosto de 1941, p. 5.
} 
los integrantes de la troupe tuvieron poco descanso, pues alternaban el trabajo con el estudio, y, en el caso de la cantatrices, la mayoría asistía a la escuela anexa al Instituto Central Femenino.

Así mismo, la colaboración de la familia fue fundamental para el buen desempeño de los pequeños, pues eran los llamados a acompañar, colaborar, orientar y hacer a sus hijos persistir en la actividad artística, lo cual no era fácil. Algunos de los pequeños artistas manifestaron espontáneamente en su primera entrevista para la prensa que, a veces se cansaban de actuar; Luzmila Gaviria, por ejemplo, quien contaba en 1941 con seis años, afirmó que en ocasiones se sentía agotada porque sus papeles eran muy largos y que en muchas funciones bostezaba en el escenario. ${ }^{70} \mathrm{Al}$ parecer, la compañía firmaba un contrato con los familiares, quienes disponían de las ganancias de los mismos. Lo anterior se demuestra en que luego de más de tres de años de trabajo, algunos artistas ya habían acumulado suficiente dinero como para ver cumplidos sus sueños, es el caso de una de las actrices, quien compró un terreno adecuado para la construcción de una casa. ${ }^{71}$

Sobre el tema del trabajo infantil, evidenciado en las entrevistas realizadas a los pequeños y las pequeñas, el Concejo Municipal se pronunció en 1943, cuando discutió un proyecto de acuerdo por el cual se rebajarían impuestos a la compañía Frutos de la Montaña. En el primer debate; el concejal Rave López, pidió que se aplazara la aprobación para otra discusión pues quería poner a consideración de la corporación la situación de los niños en la troupe. El citado Rave, aseguró que había visitado en su casa a Merceditas Escobar y tras interrogar a sus familiares sobre las condiciones en que la actriz estaba actuando en la agrupación artística, concluyó que debían analizar muy bien la posibilidad de otorgar la subvención, pues para él, "el director de la compañía no hace sino explotar a los niños". A esta afirmación se sumó la intervención del concejal Tulio Gaviria Uribe, quien expresó estar en desacuerdo con subvencionar a los artistas, pues dicho apoyo contribuiría aún más al abuso laboral; según el edil “[...] es todo el mundo el que se convierte en explotador: nosotros, que vamos al teatro a explotar la vanidad de los pequeños. Quién, de los que están aquí y tienen su hija desearían verla haciendo pantomimas en las tablas de un teatro?”. Estas declaraciones, avivaron la discusión, puesto que algunos concejales aseguraron que no era explotación laboral, pues eran enemigos de proporcionarles mucho dinero a los artistas debido a que las familias aprovecharían para vivir de aquellas ganancias ${ }^{72}$.

La participación de niños y de niñas en obras de teatro con ánimo de lucro, renovó la discusión sobre el trabajo infantil, el cual hasta la fecha se había reglamentado por varias Leyes, algunas citadas anteriormente y, que respondían, a la necesidad de proteger a los menores de once años, a quienes se les prohibía totalmente la posibilidad de trabajar y a los menores de catorce años, a quienes se les exigía un certificado

\footnotetext{
${ }^{70}$ El Colombiano, Medellín, 19 de agosto de 1941, p. 11.

${ }^{71}$ El Colombiano, Medellín, 30 de junio de 1942, número 9.173, año XXXI, p. 2.

${ }^{72}$ El Colombiano, Medellín, 3 de junio de 1943, p. 2.
} 
mínimo de educación. Al parecer, las anteriores disposiciones, que corresponden a la Ley 56 de 1927 y a la Ley 9 de 1930, no eran tomadas en cuenta por los empresarios teatrales, pues aquellas se referían, en el caso de los menores de catorce años, a trabajos inadecuados, que, para ellos, no era la situación del teatro ${ }^{73}$. La discusión en el Concejo se centró entonces en determinar si la actividad escénica correspondía con un trabajo, debate que concluyó en el rechazo del proyecto de acuerdo. Frente a lo anterior, dos meses después, personas de la clase pudiente de la ciudad, elevaron una petición al cabildo municipal, en la que solicitaban se reconsiderara la decisión tomada sobre la subvención a la compañía, petición que al parecer no fue tomada en cuenta y que ejemplifica las tensiones entre los diferentes sectores de la sociedad sobre las representaciones de la infancia, que en algunos casos apelaba por la protección y en otros se validaba el trabajo infantil en todas sus manifestaciones.

\section{Consideraciones finales}

Los actores y las actrices de la Compañía Juvenil de Revistas y Zarzuelas Frutos de la Montaña, aprendieron el oficio con el maestro director, con quien crecieron como artistas y para quien trabajaron parte de su niñez. La compañía representa uno de los pocos intentos que se realizaron en Medellín por consolidar una agrupación local, la cual pese a su característica de infantil, fue la que más se mantuvo en el tiempo y se convirtió en escuela para muchos artistas, de los cuales, algunos continuaron en la escena cultural local como Carmen Riera. Dado el gusto del público local por este tipo de compañías de teatro, pocas veces se cuestionó la participación de niños y de niñas en estas empresas, labor que en general veían como placentera y divertida para los pequeños y pequeñas artistas. Sin embargo, la insistente solicitud de subvenciones y de exención de impuestos que realizaba el director de la troupe, avivó la discusión sobre el trabajo infantil, el cual se había reglamentado en las primeras décadas del siglo XX en el país, en torno a la protección de la niñez. Aunque desde el Concejo Municipal, se debatió en algunas ocasiones sobre la situación laboral de los y las infantes, aparte de no entregar el apoyo económico solicitado a la compañía, no se tomaron medidas en torno al trabajo infantil, lo que demuestra la indiferencia y la casi complicidad que se tenía frente al tema, pues la consolidación de la industria antioqueña se hizo posible, en buena parte con el trabajo infantil y femenino.

Merceditas Escobar es un buen ejemplo para ilustrar la labor de los y las artistas en la compañía. ella, por ser la más visible del conjunto, permite acercarse a la intensa labor que por cerca de siete años asumieron los integrantes del elenco. La incipiente legislación local sobre la niñez, así como la ausencia de los repertorios destinados al público infantil -a exceptuando los programas radiales-, permiten inferir que, para el momento, no se contaba en Medellín con unas representaciones sociales sobre la infancia, capaces de problematizar el asunto del trabajo infantil. El trabajo de los niños y las niñas sobre las tablas, que se asociaba a la consolidación de un teatro autóctono, y que además parecía estar libre de los estereotipos de género, en cuanto

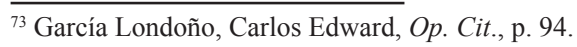


que los niños eran vistos como asexuados, hizo posible que se pensara que no era un trabajo exigente, sino que se trataba de actividades que exigían poco esfuerzo y mucha diversión para los niños.

A la discusión sobre las ganancias económicas en estas actividades, se sumarían los reconocimientos simbólicos que la sociedad colombiana brindó en diversas ocasiones a la compañía, y específicamente a Merceditas: el envío de flores, los homenajes, la dedicación de poemas de escritores reconocidos, parecían refrendar la idea de que la actuación infantil no constituía una actividad laboral. Como ha mostrado Phillipe Ariés, la infancia no es una representación intemporal, sino que responde a los imaginarios de los grupos sociales en sus diferentes contextos ${ }^{74}$; la trayectoria de la compañía estudiada y de la carrera artística de Merceditas, dan cuenta de unas elaboraciones singulares sobre la niñez, las representaciones de género y los ideales de sociedad que las puestas en escena ponían en marcha, proporcionando, además, algunos elementos para percibir los motivos por los cuales muy pocas mujeres optaron por la actuación como una profesión, un oficio que les implicaba representar y presentarse en público.

\section{Fuentes}

\section{Fuentes primarias}

\section{Prensa}

El Colombiano, Medellín, 1912-1954.

El Espectador, Medellín, 1887-1904, 1919-1920, 1922-1923.

El Pueblo, Medellín, 1871.

Crónica Municipal, Medellín, 1870-1948.

\section{Fuentes secundarias}

\section{Libro}

Aries, Philippe. El niño y la vida familiar en el antiguo régimen. Madrid: Taurus, 1987.

Castrillón Gallego. Catalina. Todo viene y todo sale por las ondas. Formación y consolidación de la radiodifusión colombiana, 1929-1954. Medellín: Universidad de Antioquia, 2015.

Gónima, Eladio. Historia del teatro en Medellín y vejeces. Medellín: Ediciones Tomás Carrasquilla, 1973.

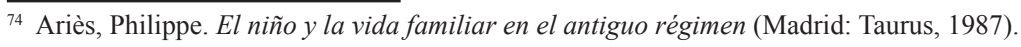


Compañias de teatro y trabajo infantil en Medellín. El caso de Merceditas Escobar en Frutos...

Lamus Obregón, Marina. Geografías del teatro en América Latina. Un relato histórico. Bogotá: Luna Libros Ltda, 2010.

Lamus Obregón, Marina. Pintores en el escenario teatral. Bogotá: Luna Libros Ltda., 2014.

Lamus Obregón, Marina. Teatro en Colombia: 1831-1886. Práctica teatral y sociedad. Bogotá: Ariel Historia, 1998.

Lamus Obregón, Marina. Teatro siglo XIX. Compañias nacionales y viajeras. Bogotá: Editorial Kimpres Ltda., 2004.

Restrepo David, Felipe. Dramaturgia en Antioquia 1880-1960. Medellín: Universidad EAFIT, 2015.

Sanín, Rafael. Historia del Teatro en Medellín. Medellín: Tipografía Industrial, 1924.

Santamaría Delgado, Carolina. Vitrolas, rocolas y radioteatros. Hábitos de escucha de la música popular en Medellín, 1930-1950. Bogotá: Pontificia Universidad Javeriana, 2014.

García Londoño, Carlos Edward. Niños trabajadores y vida cotidiana en Medellín 1900-1930. Medellín: Universidad de Antioquia, 1999.

\section{Capítulos de libros}

Scott, Joan. "El género: una categoría útil para el análisis histórico", en Lamas, Marta (com.). El género: la construcción cultural de la diferencia sexual. México: PUEG, 1996.

Toro, Cristina. "El Teatro en Antioquia", en Melo, Jorge Orlando (Dir.). Historia de Antioquia. Medellín: Suramericana de Seguros, 1991.

\section{Artículos de revista}

Velásquez, Juan Fernando. "La música, ¿un asunto de mujeres? La práctica musical como asunto de género en Medellín, visto a través de las publicaciones periódicas, entre 1886 y 1905”, en Artes La Revista, vol. IX, núm. 16 (2010), pp. 76-87.

\section{Tesis}

Correa Serna, Nancy Yohana. Teatro y sociedad en Medellín, 1880-1910, (tesis de pregrado), Universidad de Antioquia, 2004.

Correa Serna, Nancy Yohana. Mujeres en escena. De Susana Tirado a Marina Ughetti, (tesis de maestría), Universidad Nacional de Colombia, sede Medellín, 2014. 